CDD: 029.7

\title{
PLANEJAMENTO ESTRATÉGICO EMPRESARIAL: PROPOSTA DE UM SISTEMA DE INTELIGÊNCIA ORGANIZACIONAL E COMPETITIVA
}

\author{
STRATEGIC BUSINESS PLANNING: \\ PROPOSAL OF A SYSTEM OF ORGANIZATIONAL AND COMPETITIVE INTELLIGENCE
}

\author{
Orandi Mina Falsarella ${ }^{1}$ \\ Celeste Aída Sirotheau Corrêa Jannuzzi ${ }^{2}$ \\ Cibele Roberta Sugahara ${ }^{3}$
}

\begin{abstract}
RESUMO: Este trabalho tem como objetivo apresentar uma arquitetura de um Sistema de Inteligência Organizacional e Competitiva que forneça informações e subsídios para auxiliar o processo decisório, de modo que possam ser identificadas rapidamente as ameaças, oportunidades, forças e fraquezas, elementos fundamentais para a elaboração e acompanhamento do Planejamento Estratégico Empresarial. Como metodologia, foi utilizada a pesquisa bibliográfica, onde se procurou, após a definição dos principais conceitos, identificar as relações existentes entre Planejamento Estratégico Empresarial, Inteligência Organizacional e Competitiva e Sistemas de Informação. Como contribuição foi apresentada a proposta de um Sistema de Inteligência Organizacional e Competitiva, detalhado em etapas e passos, que mostra como a elaboração e acompanhamento do PEE podem ser melhor conduzidas.
\end{abstract}

PALAVRAS-CHAVE: Inteligência organizacional e competitiva. Planejamento estratégico empresarial. Sistemas de informação.

ABSTRACT: This paper aims to present an architecture of an Organizational and Competitive Intelligence System to provide information and subsidies to assist the decision making process, so that they can be quickly identified the threats, opportunities, strengths and weaknesses, key elements for the development and monitoring of the Corporate Strategic Planning. The methodology used was the literature research, which looked after the definition of key concepts, identify the relationship between Corporate Strategic Planning, Organizational and Competitive Intelligence and Information Systems. As a contribution it presented a proposed Organizational and Competitive Intelligence System, detailed in stages and steps, which shows how the preparation and monitoring of the Corporate Strategic Planning can be better conducted.

KEYWORDS: Organizational and competitive intelligence. Corporate strategic planning. Information systems

\footnotetext{
${ }^{1}$ Professor e Pesquisador do Centro de Economia e Administração da Pontifícia Universidade Católica de Campinas.Doutor em Engenharia Mecânica pela Universidade Estadual de Campinas - UNICAMP. Campinas - SP Brasil. E-mail: orandi@puc-campinas.edu.br

${ }^{2}$ Professora e Pesquisadora do Centro de Economia e Administração da Pontifícia Universidade Católica de Campinas. Doutora em Ciências da Comunicação / Ciência da Informação e Documentação pela Universidade de São Paulo - USP. Campinas - SP - Brasil. E-mail: celeste.jannuzzi@ puc-campinas.edu.br

${ }^{3}$ Professora e Pesquisadora do Centro de Economia e Administração da Pontifícia Universidade Católica de Campinas. Doutora em Ciências da Comunicação / Ciência da Informação e Documentação pela Universidade de São Paulo - USP. Campinas - SP - Brasil. E-mail: cibelesu@ puc-campinas.edu.br

Recebido em: 24/11/2013 - Aceito em: 08/04/2014
} 


\section{INTRODUÇÃ̃O}

O fato das empresas enfrentarem atualmente um ambiente turbulento, descontínuo e imprevisível impõe aos seus dirigentes a necessidade de assumir a postura de um competidor inteligente em relação à identificação, análise e utilização de informações que possam auxiliar o processo decisório. $\mathrm{O}$ uso da inteligência como sistemática do processo decisório das organizações se apresenta como um recurso de diferenciação para a obtenção de vantagem competitiva (DRUCKER, 1995; PORTER, 2005; FULD, 2007).

A Inteligência é considerada como parte essencial de uma organização que deseja obter vantagem competitiva, todavia este é um grande desafio, uma vez que, por equívoco ou um entendimento simplório de seu significado, até mesmo a mais simples das etapas de implantação do processo de inteligência na organização, ocasionalmente, enfrenta barreiras de compreensão.

Tarapanoff (2004) ressalta que a inteligência não é obtida simplesmente com base em um comportamento passivo de acesso à informação ou de conhecimento próprio, mas sim a partir de um processo de criação representada pela ativação do ciclo de inteligência, do processo de gestão da informação e do conhecimento.

A inteligência é constituída pela reunião de informações sinópticas e significativas, combinadas como um quebra-cabeça, para a orientação das decisões relacionadas às operações correntes e às estratégias competitivas da organização (JANNUZZI, 2004). Fuld (1994) refere-se à inteligência como a 'informação analisada' e exemplifica o seu entendimento dizendo que

\footnotetext{
[...] A capacidade de produção do concorrente aumentou 90\%" ou "O banco está lançando um novo produto promocional", é meramente informação. Estas somente se tornam 'inteligência geradora de decisões' quando seu enunciado apresentar implicações como: "O fabricante alcançou um padrão de custos que deverá nos colocar fora do mercado, a menos que consigamos reduzir nossos custos gerais" ou "O novo produto oferecido pelo banco não representa ameaça imediata, pois é somente uma introdução do concorrente. Podemos aguardar e observar por seis meses [...] (FULD, 1994, p.23, tradução nossa).
}

Fuld (1994) afirma que o fato de toda e qualquer empresa, independente do seu tamanho, ter a possibilidade de acessar as mesmas informações determina que a 
habilidade de transformar informação em inteligência se apresente como uma condição indispensável para que ela - empresa - seja competitiva no mercado.

Não há dúvidas sobre a importância de um programa de inteligência para as organizações, porém sua implantação não se configura como uma tarefa de fácil execução. O êxito de um programa desta estirpe está diretamente relacionado à estruturação de um sistema representado pelas etapas que constroem o processo de inteligência na organização.

Nos estudos sobre o tema, a representação dos sistemas de inteligência é normalmente definida pelas etapas de identificação de necessidades, localização das fontes de informação, coleta, tratamento e disseminação da informação. No entanto, esse entendimento se apresenta muito simples diante da complexidade requerida por um programa de inteligência, ainda mais se o sistema der suporte à elaboração e acompanhamento do Planejamento Estratégico de uma organização.

Assim, o objetivo desse trabalho é apresentar uma arquitetura de um Sistema de Inteligência Organizacional e Competitiva (SIOC) que forneça subsídios para auxiliar o processo decisório, de modo que possam ser identificadas rapidamente as ameaças, oportunidades, forças e fraquezas - elementos fundamentais para a elaboração e acompanhamento do Planejamento Estratégico Empresarial. Pretende-se, portanto, mostrar como a IOC, apoiada por SI, pode auxiliar na elaboração e acompanhamento do PEE, sendo a relação desses conceitos representada por um Sistema de Inteligência Organizacional e Competitiva.

Para o desenvolvimento deste trabalho, de natureza teórica, foi utilizada a pesquisa bibliográfica, uma vez que esta contribui para um pensamento reflexivo que permite descobrir novos fatos e relações em qualquer área de conhecimento (LAKATOS e MARCONI, 2007). A existência de diversas obras sobre os assuntos abordados no trabalho, ou seja, Planejamento Estratégico Empresarial (PEE), Inteligência Organizacional, Inteligência Competitiva e Sistemas de Informação (SI), reforçaram essa escolha.

No desenvolvimento da pesquisa foram levantados conceitos como Inteligência Organizacional e Inteligência Competitiva - principalmente, o Ciclo da Inteligência Organizacional e Competitiva - e de Planejamento Estratégico Empresarial - indicando os produtos gerados quando da elaboração do plano -, além do conceito de SI. Todos 
eles conceitos de suma relevância para a construção do objetivo proposto no presente estudo.

\section{PLANEJAMENTO ESTRATÉgICO EMPRESARIAL}

No ambiente empresarial mais do que reagir às descontinuidades importantes do mercado e adaptar as suas estratégias, as empresas devem prover ação deliberada de manter capacidades em seu interior, incluindo a busca de conhecimento de forma a antecipar as ameaças e as oportunidades.

Para Mintzberg e Quinn (2001), a estratégia é um plano que pretende integrar as principais metas, políticas e ações de uma organização de modo coerente. Quando formulada, aloca os recursos respeitando as competências e deficiências internas, além de contemplar as mudanças de ambiente causadas pelos concorrentes.

Para Thompson et. al (2008) a estratégia empresarial contempla passos competitivos e abordagens administrativas usadas por gerentes para o desenvolvimento do negócio, atração e satisfação de clientes, e para competir e alcançar os níveis esperados de desempenho organizacional.

A estratégia competitiva não pode ser vista fora dos marcos do planejamento estratégico. Di Serio e Vasconcellos (2009, p. 188) ressaltam que as empresas devem engajar-se para mudar o foco da estratégia empresarial, "deslocando-o da questão de superar seus concorrentes diretos para a expansão e/ou criação de novos mercados para seus produtos e serviços". Para os autores, o pensamento estratégico com foco na competitividade deve estar centrado em "atributos explícitos ou supostamente valorizados pelos consumidores da firma" (DI SERIO e VASCONCELLOS, 2009, p. 188)

Pode-se dizer que a estratégia competitiva consiste no esforço de estabelecer vantagem para a empresa numa perspectiva de continuidade e renovação. Para Thompson et al. (2008), a estratégia competitiva está relacionada às estratégia utilizadas de forma bem sucedida que garanta vantagem competitiva entre os concorrentes.

A possibilidade das empresas de transcender o previamente estabelecido em suas estratégias lhes conferem condição de competitividade na sociedade. Ansoff (1993) concebe o planejamento e, posteriormente, a administração estratégica, como processos 
estruturados para a elaboração de estratégias, considerando o planejamento como parte de uma análise das perspectivas da empresa, com o intuito de identificar aspectos que levem às alterações de tendências históricas e identificação de novas áreas de negócio alinhadas com as capacidades da empresa.

Nesse contexto, planejar é escolher um curso de ação e decidir, com antecedência, o que deve ser feito, como deve ser feito, quando deve ser feito e em que seqüência (MAXIMIANO, 2000; STONER, 1995). Nas organizações, o ato de planejar se apresenta como parte essencial de suas atividades, pois contribui para a sua sobrevivência no ambiente em que está inserida.

Kwasnicka (2004) aponta o planejamento como uma necessidade organizacional, uma responsabilidade administrativa que permite que a organização escolha metas baseadas em estimativas e previsões futuras. Montana e Charnov (2008) expressam o planejamento como sendo o processo de determinar os objetivos organizacionais e como atingi-los.

Segundo Rizzo e Falsarella (2006), o planejamento, como etapa do processo de gestão, busca o estabelecimento de um conjunto coordenado de ações com o propósito de atingir objetivos previamente estabelecidos. Dentro da organização, auxilia o processo de tomada de decisão quando se pretende buscar resultados a serem atingidos.

A ênfase no planejamento enquanto etapa do processo de gestão requer o envolvimento da alta administração usualmente preocupada com o retorno posterior ao desenvolvimento do planejamento estratégico. Ansoff e McDonnell (1993) reconhecem ser o apoio da alta administração condição primordial, mas não suficiente para garantir a eficácia do planejamento estratégico da empresa.

Anthony e Govindarajan (2001) afirmam que o processo pelo qual se decide como implementar as estratégias é conhecido como Planejamento Estratégico Empresarial (PEE). O PEE considera os objetivos e as estratégias aprovadas e procura desenvolver programas para o cumprimento eficiente e eficaz das estratégias.

Os resultados esperados com a elaboração do PEE de acordo com Montana e Charnov (2008) devem nortear a gestão estratégica institucional, especificamente a sua visão de futuro, missão, objetivos e metas, pois devem incluir caminhos que permitam a instituição avançar, de modo a conseguir selecionar áreas de mercado que deve ou não atuar, ou continuar atuando. 
Rezende (2002) diz que para elaborar um PEE é necessário analisar as ameaças e oportunidades, avaliando o ambiente externo e os pontos fracos (fraquezas) e fortes (forças) com olhar para o ambiente interno e, desse modo, traçar o caminho que uma organização deseja seguir.

Em outras palavras, o PEE é um processo que consiste na análise sistemática dos pontos fortes e fracos da empresa, e das oportunidades e ameaças do meio ambiente em que ela atua com o intuito de estabelecer objetivos, estratégias, metas e ações que possibilitem um aumento da competitividade empresarial (RIZZO; FALSARELLA, 2006).

Em complemento, Ansoff e McDonnell (1993, p. 301) advertem que no enfoque original do planejamento estratégico supunha-se que "as novas estratégias deviam tirar proveito dos pontos fortes tradicionais e evitar os pontos fracos da empresa". Nesse contexto, acreditava-se que as potencialidades tradicionais podiam ser as mesmas, enquanto a estratégia sofria alterações. Para os autores o ambiente dinâmico e descontínuo impõe repensar suas estratégias visto que "os pontos fortes tradicionais se transformam, por definição, em pontos fracos futuros".

De fato, pode-se dizer que as empresas devem elaborar o PEE enfrentando o reduzido grau de estabilidade do mercado e sendo ágil o suficiente para alterar a estratégia visando obter impacto significativo na competitividade.

Assim, é possível definir que o PEE, quando elaborado, define a visão de futuro, a missão, os objetivos e metas que devem ser alcançadas e as estratégias utilizadas para que os propósitos de uma instituição sejam satisfeitos.

A partir da aprovação do PEE inicia-se a etapa da execução, onde ocorre a materialização dos planos por meio da execução das estratégias. A etapa de acompanhamento tem como propósito avaliar desvios entre o que foi planejado e o que se executou, provendo ações de melhorias e correções, quando necessárias.

\section{A INTELIGÊNCIA ORGANIZACIONAL E COMPETITIVA}

Estudos sobre a inteligência nas organizações ganharam profundidade diante do ambiente econômico cada vez mais competitivo e pelos avanços significativos das tecnologias de informação e comunicação. Este contexto contribuiu para o surgimento 
de conceitos como Inteligência Organizacional e Inteligência Competitiva. O primeiro, Inteligência Organizacional, conforme Starec (2006, p.49), refere-se ao gerenciamento estratégico da informação na organização e corresponde às "respostas rápidas, quase que instantâneas para a tomada de decisão". O segundo conceito, Inteligência Competitiva, refere-se, de acordo com Fuld (1994), ao monitoramento do ambiente competitivo que envolve a organização, a fim de mantê-la à frente da concorrência.

\subsection{Inteligência Organizacional}

A Inteligência Organizacional é definida pela capacidade da empresa de movimentar seu capital intelectual em prol da missão traçada para ela. Para Albrecht (2004), o desenvolvimento da Inteligência Organizacional requer, primeiramente, que a empresa seja avaliada a partir das seguintes dimensões, detalhadas na Figura 1: (a) Visão estratégica, (b) Destino compartilhado, (c) Apetite por mudanças, (d) "Coração", (e) Alinhamento e congruência, (f) Uso do conhecimento e (g) Pressão por desempenho.

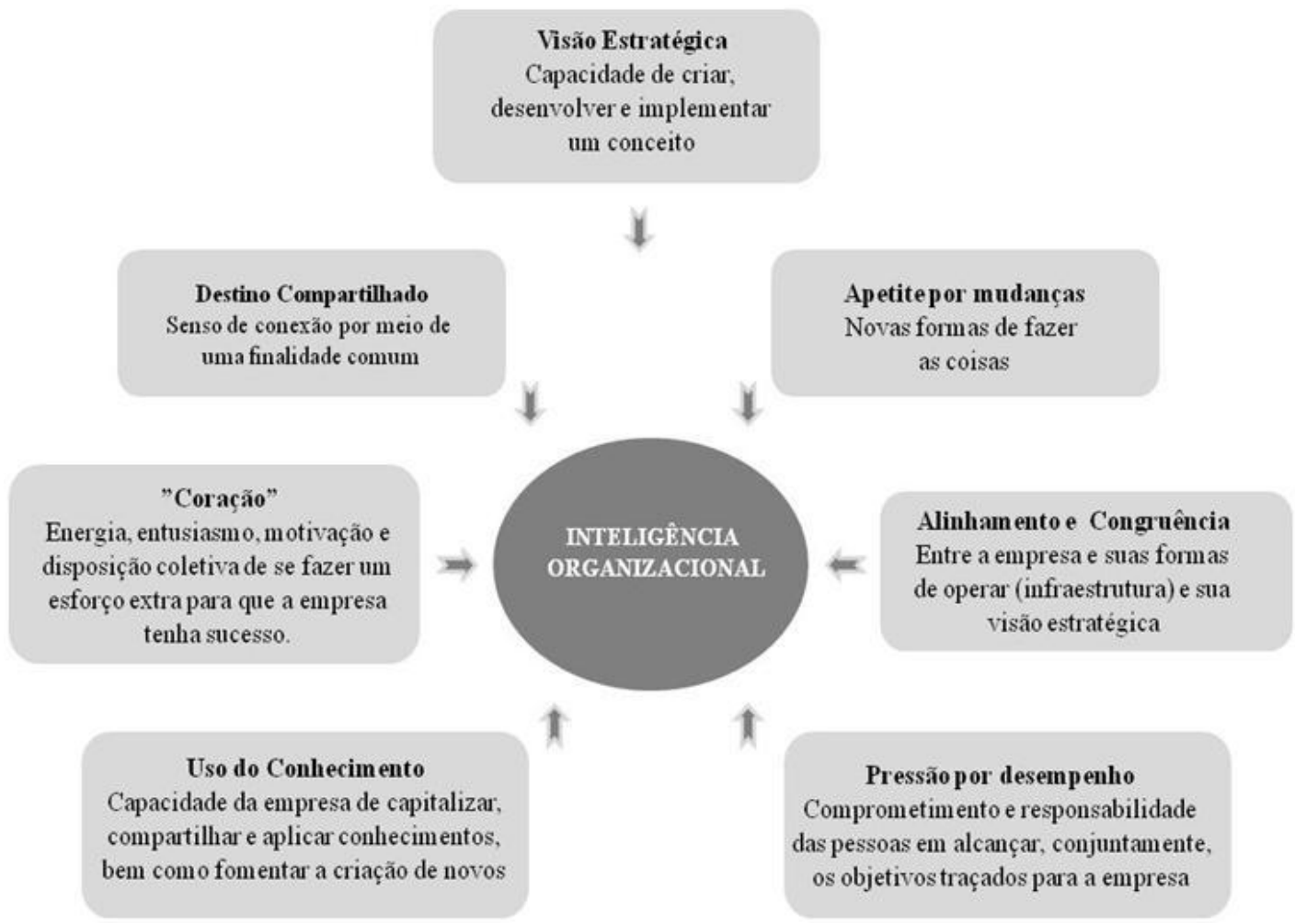

FIGURA 1 - O modelo de inteligência organizacional

Fonte: Figura e conteúdo adaptado de Albrecht, 2004. 
A Inteligência Organizacional pode ser caracterizada de duas formas: como um produto (de caráter estático) e como um processo (de caráter dinâmico), ambas mutuamente dependentes que se fazem presentes em um ciclo contínuo de atividades da organização (MORESI, 2001).

Como um produto, ela refere-se à totalidade da informação estruturada, sintetizada e direcionada para um objetivo, que é gerada quando o sistema de informação de uma organização aumenta a sua capacidade de solução de problemas. Quatro níveis de produto podem ser distinguidos [...]: (1) dados (de natureza física e formal em sua caracterização); (2) informação (tipo significativo relativo aos objetivos de uma organização); (3) conhecimento (informação de valor agregado aplicada a um problema); (4) inteligência (conhecimento usado ativamente) (MORESI, 2001, p.44).

Como um processo, a inteligência organizacional é interativa, agregadora e uma complexa coordenação das inteligências humana e de máquina dentro de uma organização. Isso implica que estas inteligências, humana e de máquina, sejam orientadas em direção a processos de fluxo de trabalho (MORESI, 2001, p.44).

Assim, dentro de um ciclo de permanente renovação, definido a partir de uma arquitetura informacional bem pensada que alimenta continuamente a geração e uso da informação e do conhecimento na empresa (vide figura 1), é que a Inteligência Organizacional ganha significativa importância na fundamentação do processo decisório e na capacidade da empresa de atuar em seu ambiente competitivo.

\subsection{Inteligência Competitiva}

As organizações que almejam vantagem competitiva dão uma importância significativa para a Inteligência Competitiva (IC). Inicialmente, contemplando apenas a coleta de dados sobre a concorrência, a IC amplia o seu conceito que passa a considerar, entre outros fatores, a tomada de decisão estratégica nas organizações. Essa evolução da Inteligência Competitiva pode ser observada na descrição de Prescott (1999) que aponta quatro estágios deste progresso, a saber:

1. Coleta de dados competitivos (antes do final dos anos 1970) - nesse estágio havia coleta de dados competitivos dos concorrentes para atender processos 
informais ad hoc. A análise, quando realizada, era limitada e havia pouco envolvimento da alta administração;

2. Análise da indústria e dos competidores (início dos anos 1980) - nesse estágio as unidades de IC começam a emergir. A análise de dados ainda era limitada e se restringia a dados quantitativos, a ênfase era dada ao nível tático e não às decisões estratégicas e o envolvimento da alta administração ainda era superficial;

3. Inteligência Competitiva para tomada de decisões estratégicas (1988 a 1999) - Nesse estágio havia uma crescente preocupação com implicações estratégicas. Surgiam evidências de que a IC poderia ajudar gestores identificando novas oportunidades de negócios, além de evitar surpresas desagradáveis. Surgiu também a preocupação se os Sistemas de Informação poderiam criar, acessar e interagir com dados internos e externos, de modo a facilitar os gerentes no processo de tomada de decisão. A análise dos dados eram quantitativos e qualitativos;

4. Inteligência Competitiva como parte essencial da empresa (futuro) - A análise de dados e informações será ampla e a informação qualitativa dominará a quantitativa. A inteligência estará integrada ao processo de tomada de decisões estratégicas, muitas vezes com o apoio de sofisticados sistemas de informação. A alta administração usará IC como meio para antever o futuro da organização e a considerará como parte integrante da aprendizagem organizacional.

O estágio indicado pelo autor como referente ao futuro já é uma realidade para muitas organizações nos dias de hoje. Cada vez mais, a IC assume o papel fundamental de atuar como intermediadora entre o ambiente competitivo e o processo estratégico de uma organização (OLIVEIRA et al., 2013). Esse papel mediador pode ser ilustrado conforme apresentado na figura 2 a seguir. 


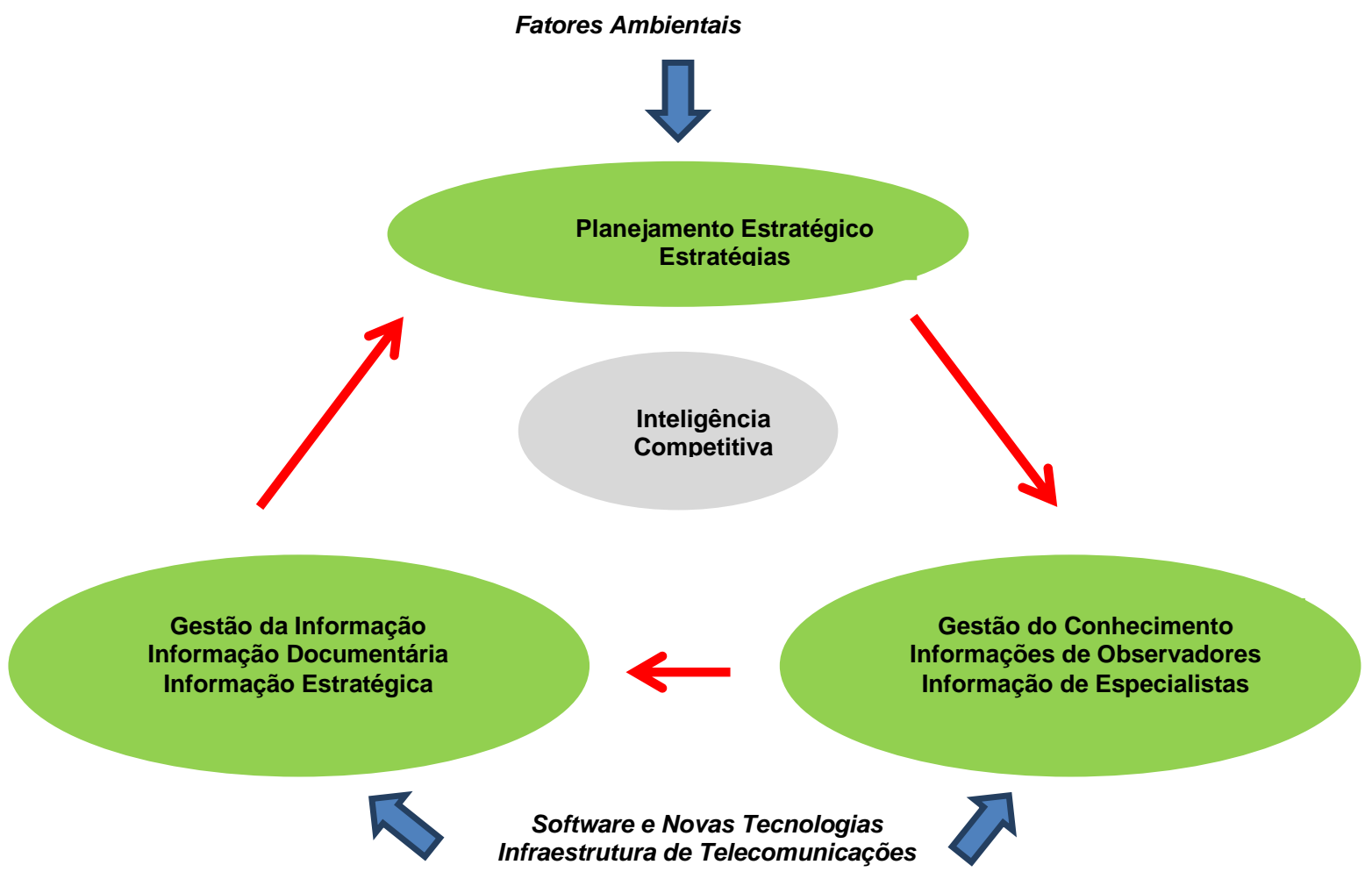

FIGURA 2 - Relações da Inteligência Competitiva

Fonte: Tarapanoff, 2004, p.18.

Restrito ou mais abrangente, o conceito de Inteligência Competitiva teve suas fronteiras ampliadas ao longo do tempo. Definida, inicialmente (década 1970-80), como o monitoramento da concorrência a fim de obter informações que auxiliassem a tomada de decisão e o planejamento estratégico, a Inteligência Competitiva foi ganhando importância e conteúdo em relação ao seu papel nas organizações. Essa percepção sobre a IC varia tanto em relação ao tempo como também em termos geográficos, como, por exemplo, nos Estados Unidos, França etc.

Na tradição francesa, a inteligência competitiva é entendida de forma mais
ampla, incluindo a busca de qualquer informação na ambiência, de caráter
tecnológico, social ou político, inclusive sobre os seus competidores, que
possibilite um melhor posicionamento da organização na ambiência. É um
modelo de gestão organizacional que contempla: gestão da informação,
gestão estratégica e gestão do conhecimento apoiando-se num sistema de
inteligência baseado no ciclo de gestão da informação, nas tecnologias da
informação, em sistemas de informação e redes de especialistas (L'État de
nouvelles technologies de linformation en 1998) (TARAPANOFF, 2001,
p.17).

Ainda sobre o entendimento dos estudiosos franceses, Tarapanoff (2001, p.17) ressalta que, "sob esta orientação, o planejamento estratégico depende dela e a gestão da 
informação e do conhecimento é complementar a ela. Estes três elementos se integram e se realimentam".

Diante de um cenário cada vez mais desafiador, a Inteligência Competitiva (IC) tem sido considerada como um programa de fundamental importância para as organizações, pois, quando bem aplicado, auxilia na redução de riscos no processo de formulação e implementação de estratégias competitivas e possibilita que a empresa esteja mais preparada para possíveis ameaças, bem como oportunidades advindas de seu ambiente, etc. (OLIVEIRA et al., 2013).

\subsection{Inteligência Organizacional e Competitiva}

O reconhecimento da importância da Inteligência Organizacional e da Inteligência Competitiva para as organizações, aliado ao fato de serem complementares em suas proposições, favorecendo ainda mais a obtenção de vantagem competitiva, contribui para um conceito mais amplo representado pelo termo Inteligência Organizacional e Competitiva (IOC).

Diante do que representa e propicia para uma organização, a IOC pode contribuir com o Planejamento Estratégico Empresarial ao monitorar o ambiente interno, analisando forças e fraquezas, e o ambiente externo, avaliando ameaças e oportunidades, quando o PEE está sendo elaborado e também quando ele está sendo executado, permitindo rapidamente mudanças de estratégias, quando necessárias. Esse processo pode ser suportado pelas etapas do ciclo da inteligência, conforme descrito por Alves e Falsarella (2009, p. 317-318) e sintetizado a seguir:

$\checkmark$ Planejamento - é determinado o campo de interesse que uma organização pretende observar, definida a demanda e as fontes de informação e descrito as necessidades e finalidades. Nessa etapa, procura-se identificar que dados e informações são importantes e podem fornecer subsídios à etapa de análise;

$\checkmark$ Coleta de dados e informações - tem início após a identificação das fontes de informação;

Análise - procura identificar padrões e tendências significativas, por meio da busca de relações, até então não encontradas entre os dados; 
$\checkmark$ Disseminação - é essa etapa que se preocupa em entregar a informação tratada e analisada para o usuário final em um formato adequado, de modo que ele possa tomar a decisão mais adequada.

Analisando as etapas e a necessidade de que sejam fornecidas informações e subsídios para o processo decisório, de modo que possam ser identificadas rapidamente as ameaças, oportunidades, forças e fraquezas - elementos fundamentais para a elaboração e acompanhamento do Planejamento Estratégico Empresarial - é possível pensar na criação de um sistema, cujas fontes de dados e informações sejam provenientes de diversos tipos de Sistemas de Informação (SI).

Assim, quando se analisa a inteligência no contexto das estratégias competitivas e o quarto estágio apresentado por Prescott (1999), não há dúvidas de que a aplicação desse conceito passa a ser fundamental e pode dar suporte à elaboração e acompanhamento do Planejamento Estratégico Empresarial (PEE), principalmente se, para esse propósito, for criado um SI que permita buscar informações internas e externas, estruturadas e não estruturadas que possam ser analisadas, gerando inteligência, com o propósito de permitir que as áreas gerenciais e estratégicas das empresas possam ter subsídios para tomar decisão quando necessitarem avaliar ameaças, oportunidades, forças e fraquezas.

\section{SISTEMAS DE INFORMAÇÃO}

Alves e Falsarella (2009, p. 316) afirmam que "a inteligência, remetida ao contexto da informação, está geralmente relacionada a um ato, a uma ação de escolha da melhor alternativa dentre todas analisadas, baseadas nas informações obtidas”. Para que isso se torne viável, é de suma importância que as informações se apresentem organizadas e contextualizadas, segundo a necessidade a qual ela atende.

Segundo Falsarella (2001, p.52), quando se fala em informação, devem ser enfatizados os Sistemas de Informação (SI) "que permitem a coleta, o armazenamento, a recuperação e a disseminação de informações. SI são, hoje, quase sem exceção, baseados em computador e apóiam as funções operacionais, gerenciais e de tomada de decisão existentes na organização". 
Canongia et al (2001) defende o desenvolvimento de um Sistema de Informação Estratégico que tem como um dos objetivos organizar, disponibilizar e analisar informações estratégicas e táticas, tanto no ambiente interno propiciando compartilhamento e renovação, como no externo, auxiliando relações de parcerias e análises de tendências, identificando oportunidades e buscando soluções para manutenção e criação de vantagem competitiva. Nesse contexto, mas dentro de uma concepção mais ampla, de monitoramento contínuo do ambiente, é que podem ser construídos os sistemas de inteligência, ou programas de inteligência, cuja orientação metodológica mais básica se fundamenta na identificação de fontes e coleta de informações, tratamento destas informações, por meio de técnicas analíticas, e na condução das decisões.

Bataglia (1999) relata que um sistema de inteligência competitiva tem como insumos informações importantes para uma empresa se manter competitiva e dominar o mercado, devendo focar no posicionamento de mercado e nas metas estratégias. A autora ainda conclui que

Um sistema genérico de inteligência competitiva deve ser capaz de contemplar as dimensões tecnológica, econômica, política e social. Funciona como uma antena na identificação de novas oportunidades e sinais de mudanças no ambiente. Ao mesmo tempo, ajuda a empresa a não perder o foco estratégico no processo de coleta, armazenamento e análise da informação(BATAGLIA, 1999, p. 204).

Valentim et al (2003) corrobora com Bataglia quando descreve que os executivos necessitam de sistemas de informação que monitorem, coletem e analisem informações do ambiente externo que são úteis para o PEE. A autora destaca ainda

O monitoramento precisa selecionar cuidadosamente, dentre um grande volume de informações, aquelas que têm potencial relevância, assim como deve funcionar como uma antena na identificação de novas oportunidades e sinais de mudanças no ambiente. Ao mesmo tempo, deve ajudar a empresa a não perder o foco estratégico no processo de coleta, armazenagem, análise e disseminação da informação (VALENTIM, 2003, p. 8).

No que se refere a sistemas de informação é possível verificar vários tipos aplicados à empresa. De acordo com Falsarella et al. (2010), os diferentes tipos de sistemas de informação podem ser classificados na empresa como:

Sistemas de Informação Transacionais - são necessários para o controle operacional das organizações, pois é através deles que ocorrem os registros das operações realizadas na empresa; 
Sistemas de Informação Gerenciais - são sistemas que possibilitam gerentes de nível médio visualizar o desempenho de seu departamento, bem como controlar as atividades realizadas na empresa. Este tipo de sistema realiza combinações de dados advindos dos registros dos sistemas transacionais;

$\checkmark$ Sistemas de Apoio à Decisão - são sistemas que não só fornecem informações para apoio à tomada de decisão, mas também, com os recursos que disponibilizam, contribuem para o processo de tomada de decisão;

$\checkmark$ Sistemas de Informação para Executivos e de Inteligência de Negócios - são sistemas que abastecem a alta gerência com informações estruturadas e não estruturadas e sumarizadas provenientes de fontes internas e externas.

Os sistemas de Informação para Executivos e de Inteligência de Negócios (ou Inteligência Empresarial ou Business Intelligence), tem sido cada vez mais utilizados na tomada de decisão por parte das organizações. Esse tipo de sistema faz uso de informações internas e estruturadas da organização, mas também de informações externas e não estruturadas advindas do monitoramento do ambiente que envolve a organização. Inúmeros são os recursos oferecidos por este tipo de sistema, daí a possibilidade de se aplicar a plataforma de Inteligência de Negócios em outros contextos (Sistemas de Informações Gerenciais, Sistemas de Gestão do Conhecimento, Sistemas de Apoio à Decisão etc.), permitindo a personalização da ferramenta (O'BRIEN e MARAKAS, 2013).

\section{PROPOSTA DE UM SISTEMA DE INTELIGÊNCIA ORGANIZACIONAL E COMPETITIVA}

Após as discussões anteriores, entende-se que durante a elaboração do PEE, quando se analisam ameaças e oportunidades e forças e fraquezas, é fundamental possuir dados e informações confiáveis para auxiliar e subsidiar o processo decisório. No entanto, para atender a esse requisito, é imprescindível que as informações internas e externas, as estruturadas e as não estruturadas e as destinadas aos usuários de níveis estratégicos e táticos estejam sistematizadas e sejam, portanto, provenientes de SI.

Entende-se também, que após a elaboração do PEE, quando o mesmo começa a ser executado, o ambiente onde uma instituição atua, tanto internamente como 
externamente não é estático. Nesse caso, novas ameaças ou oportunidades e novas forças ou fraquezas podem estar acontecendo sem ao menos estar sendo retratado no PEE. Assim, é fundamental e necessário que esse ambiente seja constantemente monitorado, reforçando, mais uma vez, a necessidade desse processo ser sistematizado.

Ao extrair dados e informações com vistas a subsidiar o processo decisório na elaboração e acompanhamento do PEE requer aplicar o ciclo da inteligência, denominado nesse estudo de Ciclo da Inteligência Organizacional e Competitiva (IOC), de modo que seja definido o campo de interesse que se pretende observar, as fontes de informação e o processo de coleta, a análise e busca de relações e a entrega das informações tratadas e analisadas em um formato adequado para que os responsáveis pelo PEE possam tomar as decisões mais assertivas.

A Inteligência Organizacional é contemplada no ciclo IOC pelo fato de envolver a inteligência humana e de máquina dentro da organização, conforme indicado por Moresi (2001). Também pode se destacar as dimensões representadas pelo alinhamento e pela congruência, bem como pelo uso do conhecimento, apontados no modelo de Albrecht (2004), apresentado anteriormente neste trabalho. A Inteligência Competitiva, por sua vez, é contemplada no ciclo da IOC nas relações ilustradas por Tarapanoff (2004) ao referir-se ao Planejamento Estratégico, definido a partir dos fatores ambientais, e pela gestão da informação e do conhecimento, suportados pelos softwares e novas tecnologias e infra estrutura de telecomunicações, conforme já mencionado.

A figura 3, a seguir, procura representar a relação entre PEE, IOC e Sistemas de Informação por meio da proposta de um Sistema de Inteligência Organizacional e Competitiva (SIOC) que forneça informações e subsídios para auxiliar o processo decisório, de modo que possam ser identificadas rapidamente as ameaças, oportunidades, forças e fraquezas, elementos fundamentais para a elaboração e acompanhamento do Planejamento Estratégico Empresarial.

Para que isso seja possível, os vários tipos de Sistemas de Informação devem fornecer insumos, sejam eles Transacionais, Gerenciais, de Apoio à Decisão ou de Informação para Executivos e de Inteligência de Negócios.

Procurando detalhar essa relação são descritas a seguir as etapas do SIOC e por meio dos passos de 1 a 5, como ele se comportará (vide figura 3). 
Para a elaboração do PEE, é fundamental descobrir forças e fraquezas e ameaças e oportunidades. Assim, deve haver um forte relacionamento com o Ciclo da IOC, onde na etapa de Planejamento do Ciclo da IOC, passo 1, deve ser definido o campo de interesse que a organização pretende observar e as fontes de informação. Também deve ser identificado quais dados e informações podem ser úteis levando a novas oportunidades e ameaças, além de sinalizar forças e fraquezas.

\section{Sistema de Inteligência Organizacional e Competitiva}

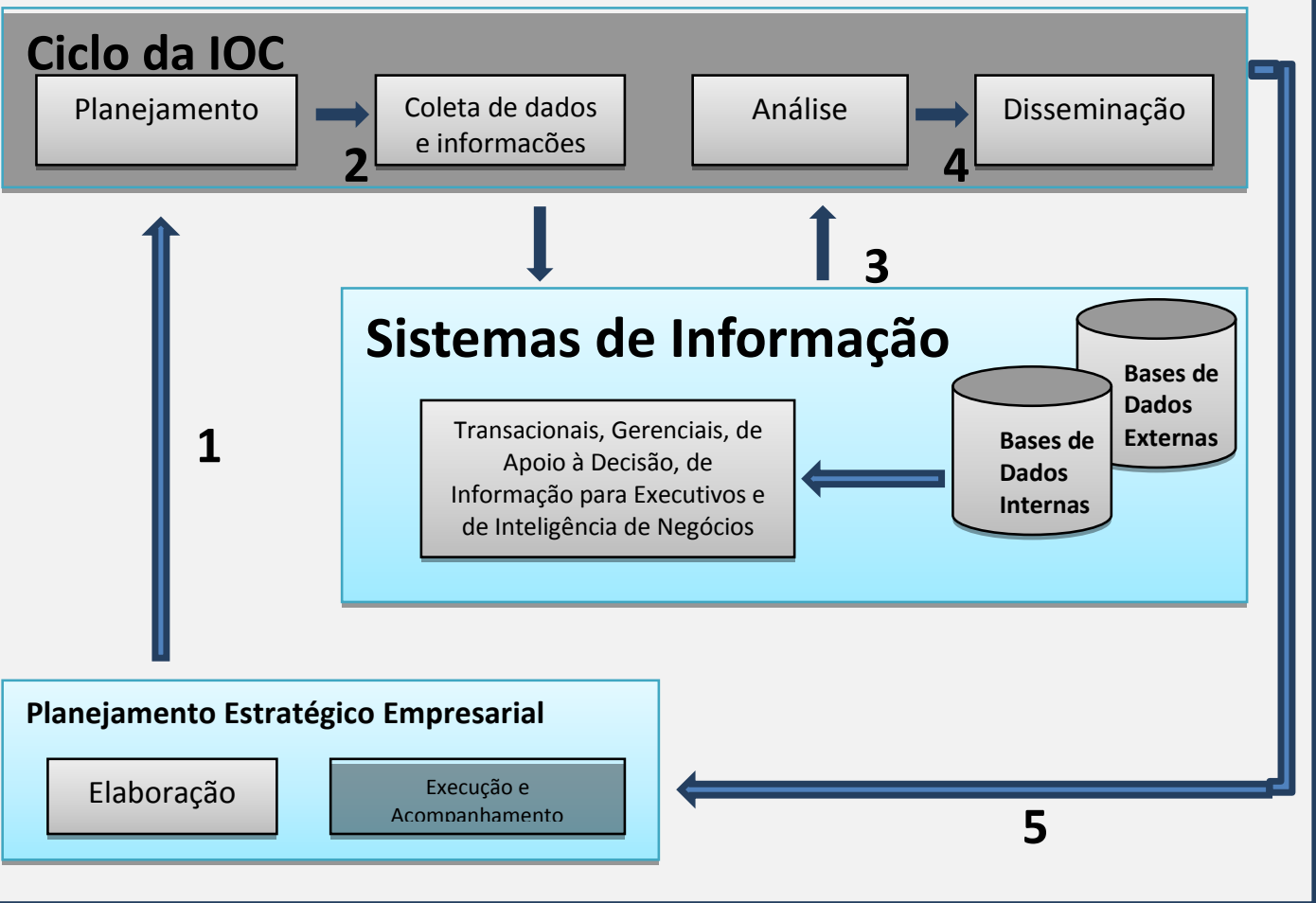

FIGURA 3 - Sistema de Inteligência Organizacional e Competitiva Fonte: Elaborada pelos autores

Nota-se que a etapa de Planejamento é realizada por pessoas, pois somente os gestores no contexto do PEE poderão dizer quais serão os campos de interesse que a organização pretende observar e onde os dados e informações deverão ser buscados, considerando-se todas as dimensões: econômica, tecnológica, política e social.

Uma vez realizada a etapa de Planejamento, inicia-se o passo 2, onde é realizada a etapa de Coleta de Dados e Informações. Nessa etapa, devem ser relacionados os SI que serão úteis e que deverão fornecer os dados e informações. Assim, serão acessados 
os Sistemas de Informações Transacionais, Gerenciais e de Apoio à Decisão, responsáveis pelo fornecimento de dados e informações internas e estruturadas, para que sejam analisadas as forças e fraquezas. Também serão acessados os Sistemas de Apoio à Decisão e de Informação para Executivos e de Inteligência de Negócios, responsáveis por fornecer informações internas e externas, estruturadas e não estruturadas.

De posse da necessidade das informações descritas na fase de Planejamento do Ciclo da IOC, deve-se buscar nas bases de dados internas e externas os dados e as informações solicitadas.

Com os dados e informações (passo 3) é possível iniciar a etapa de Análise do Ciclo da IOC onde, após a análise e busca de relações, podem emergir ameaças e oportunidades e forças e fraquezas.

Um ponto importante que também merece destaque é que tanto a fase de Coleta de Dados e Informações, como a de Análise, pelo fato de serem realizadas com o apoio de sistemas de informação, devem ser automatizadas, permitindo, desse modo, avaliar um grande volume de dados e informações disponíveis no ambiente de atuação da organização. Nesse caso, a busca por dados e informações transacionais estruturadas e internas ou não estruturadas e externas, alimenta os sistemas de Apoio à Decisão e de Informação para Executivos e de Inteligência de Negócios, de modo que os gestores do PEE possam ter subsídios para auxiliar o processo decisório.

Ao final da fase de Análise, inicia-se a etapa de Disseminação (passo 4), onde a informação tratada e analisada será entregue para os usuários (passo 5) para que estes possam tomar a decisão mais adequada, contribuindo, assim, com o processo de elaboração do PEE. Obviamente, esses passos podem ser feitos e refeitos várias vezes até que a elaboração do PEE esteja completamente finalizada.

Paralelamente ao início da execução do PEE, inicia-se o acompanhamento do plano, onde o SIOC pode fornecer informações e subsídios para que seja verificado pelos gestores do PEE se as estratégias adotadas estão dando resultado.

Além disso, no acompanhamento do PEE, o SIOC pode constantemente monitorar novas ameaças e oportunidades e novas forças e fraquezas, tornando o PEE dinâmico, passível de percepções e correções rápidas, logo que desvios ou novas necessidades forem descobertas. Assim, as etapas do Ciclo da IOC devem ocorrer de 
forma constante e contínua, permitindo que todo o processo seja monitorado, avaliado e revisado.

Após a descrição das etapas, visando tornar mais claro o entendimento do SIOC, exemplifica-se a seguir como este sistema poderá fornecer informações e subsídios para auxiliar gestores no processo decisório, identificando ameaças e oportunidades e forças e fraquezas durante a elaboração e acompanhamento do PEE. Nesse caso, será utilizado como exemplo, de modo fictício, uma Instituição de Ensino Superior (IES)

Exemplificando o passo 1 e o relacionamento com a etapa de Planejamento do Ciclo da IOC, pode ser definido como campo de interesse observar os concorrentes externos que atuam na cidade onde a IES presta seus serviços, além de tendências do ensino superior buscando, dessa forma, descobrir ameaças e oportunidades. No caso das forças e fraquezas poderia ser observada a titulação e o regime de trabalho dos docentes perante as exigências dos órgãos regulatórios governamentais e a sustentabilidade econômica e financeira da IES.

Quanto às fontes de informação, para as ameaças e oportunidades, poderiam ser utilizados os dados disponíveis nas redes sociais e portais das IES concorrentes, além de informações provenientes do Censo da Educação Superior fornecido pelo Instituto Brasileiro de Geografia e Estatística (IBGE). No caso das forças e fraquezas, o Sistema Contábil e Financeiro, além do Sistema de Carreira Docente que poderia trazer informações úteis.

Assim, inicia-se o passo 2, ou seja a etapa de Coleta de Dados e Informações nos sistemas internos e externos à IES, buscando informações, sejam elas estruturadas ou não estruturadas.

De posse das informações (passo 3), inicia-se a etapa de Análise do Ciclo da IOC buscando relações que serão exemplificadas a seguir:

$\checkmark$ Analisando os dados do IBGE, verifica-se como tendência o aumento da expectativa de vida da população nos últimos anos e a diminuição do número de jovens na idade de ingressarem no ensino superior;

$\checkmark$ Analisando as informações dos concorrentes, percebe-se que alguns deles estão sendo referenciados nas redes sociais negativamente por conta da qualidade do ensino, enquanto outros são referenciados positivamente por 
utilizar técnicas pedagógicas proporcionadas pelo uso de novas tecnologias de ensino;

$\checkmark$ Ao analisar os portais dos concorrentes observa-se que cursos novos serão oferecidos, sendo muitos deles os mesmos já são oferecidos pela IES. Além disso, observa-se também que os concorrentes estão anunciando o oferecimento de cursos inéditos.

$\checkmark$ Ao analisar as informações provenientes do Sistema Contábil e Financeiro observa-se que a capacidade de investimento da IES vem diminuindo ao longo do tempo, fato que pode comprometer a sua competitividade;

$\checkmark$ Ao analisar o Sistema de Carreira Docente, nota-se que todos os cursos possuem docentes com titulação e regime de trabalho atendendo o que é exigido pelos órgãos reguladores.

Ao final dessa fase, no passo 4, ocorre a etapa de Disseminação da Informação, podendo os usuários tomar as decisões quanto a ameaças e oportunidades e forças e fraquezas (passo 5), conforme descrito no quadro 1.

QUADRO 1 - Exemplos de Ameaças, Oportunidades, Forças e Fraquezas

\begin{tabular}{|c|c|c|c|c|}
\hline $\begin{array}{l}\text { Fase de Análise } \\
\text { do }\end{array}$ & Ameaças & Oportunidades & Forças & Fraquezas \\
\hline \multicolumn{5}{|l|}{ Ciclo da IOC } \\
\hline $\begin{array}{l}\text { Envelhecimento } \\
\text { da população }\end{array}$ & & $\begin{array}{l}\text { Oferecer cursos } \\
\text { diferenciados } \\
\text { para esse } \\
\text { público }\end{array}$ & & \\
\hline $\begin{array}{l}\text { Diminuição do } \\
\text { número de jovens } \\
\text { em idade de } \\
\text { cursar o ensino } \\
\text { superior }\end{array}$ & $\begin{array}{l}\text { Diminuição do } \\
\text { número de } \\
\text { ingressantes }\end{array}$ & & & \\
\hline $\begin{array}{l}\text { Baixa qualidade } \\
\text { de ensino dos } \\
\text { concorrentes }\end{array}$ & & $\begin{array}{l}\text { Diferenciar-se } \\
\text { pela qualidade } \\
\text { de ensino }\end{array}$ & & \\
\hline $\begin{array}{l}\text { Concorrentes } \\
\text { utilizando } \\
\text { técnicas } \\
\text { pedagógicas }\end{array}$ & $\begin{array}{l}\text { Perda de } \\
\text { alunos para os } \\
\text { concorrentes }\end{array}$ & & & \\
\hline
\end{tabular}




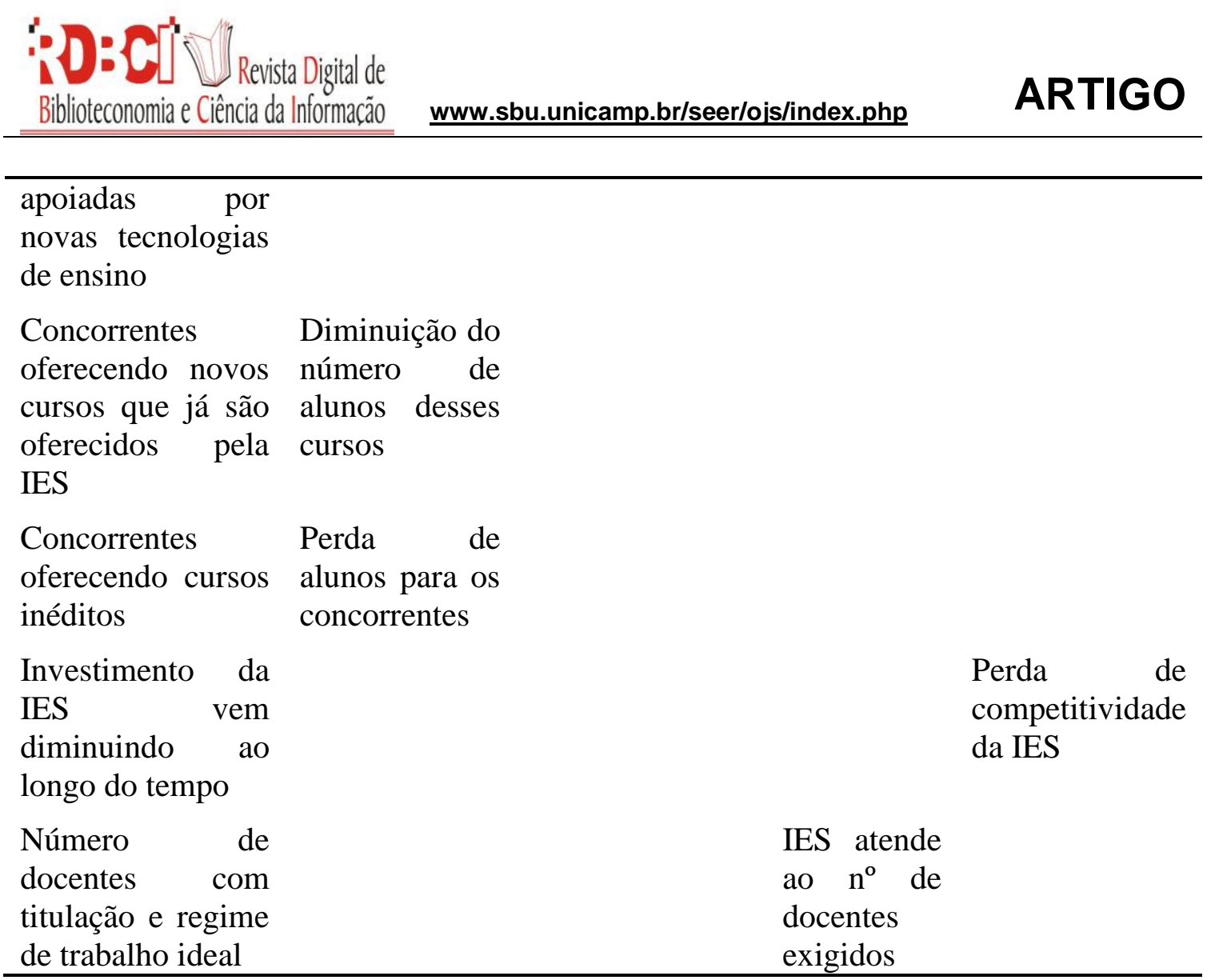

Fonte: Elaborado pelos autores.

Após a análise das ameaças e oportunidades, forças e fraquezas, definição dos objetivos estratégicos e início da fase de execução do plano, inicia-se a etapa de acompanhamento, podendo esse ciclo ser repetido novamente a partir do passo 1 .

Nesse caso, as etapas do Ciclo da IOC devem ser refeitas, novos dados e informações devem ser coletados, novas análises devem ser realizadas e a entrega de informações tratadas e analisadas para os usuários devem ocorrer de forma constante e contínua, permitindo que todo o processo seja monitorado, avaliado e revisado continuamente.

\section{CONSIDERAÇõES FINAIS}

O Sistema de Inteligência Organizacional e Competitiva apresentado nesse trabalho mostrou como a elaboração e o acompanhamento do PEE pode utilizar as etapas do Ciclo da IOC e como ocorre a integração com os vários tipos de SI na busca de informações internas e externas, sejam elas estruturadas ou não estruturadas e como 
o processo de análise pode ser útil para a descoberta de ameaças e oportunidades e de forças e fraquezas.

O sistema proposto reforça o estágio da Inteligência Competitiva como parte essencial da empresa (futuro) proposto por Prescott (1999), pois apresenta como a análise de dados e informações poderá contribuir para gerar inteligência e estar integrado ao processo de tomada de decisões estratégicas com o apoio de Sistemas de Informação, sejam eles transacionais, gerenciais, de apoio à decisão, de apoio ao executivo e de inteligência de negócios permitindo que a alta administração utilize a IOC para monitorar o ambiente onde a instituição atua.

O estudo apresentado evidencia que a etapa de Planejamento do Ciclo da Inteligência Organizacional e Competitiva (IOC) é uma das mais importantes, pois, embora seja realizada por gestores do Planejamento Estratégico Empresarial (PEE), ela determina o campo de interesse que uma organização pretende observar, onde se procuram identificar quais dados e informações são importantes. Em outras palavras, identificar quais dados e informações são úteis e que podem levar a novas oportunidades, ameaças, forças e fraquezas, fornecendo subsídios à etapa de análise e auxiliando, assim, o processo decisório que envolve o PEE.

Uma análise comparativa entre os conceitos Planejamento Estratégico Empresarial, Sistemas de Informação, Inteligência Organizacional e Inteligência Competitiva mostrou que estes se complementam em suas proposições, fornecendo elementos fundamentais para a construção do Sistema de Inteligência Organizacional e Competitiva e do ciclo que o compõe. Isso fica evidenciado na arquitetura proposta para o referido sistema.

A pesquisa também possibilitou delinear os parâmetros básicos e necessários para descrever como as etapas do Ciclo da Inteligência Organizacional e Competitiva e quais tipos de Sistemas de Informação são adequados para elaboração e acompanhamento do Planejamento Estratégico Empresarial.

Finalmente, destaca-se a importância das etapas de Coleta de Dados e Informações e de Análise serem realizadas com o apoio de Sistemas de Informação automatizados, pois estes permitem avaliar um grande volume de dados e informações disponíveis no ambiente de atuação da organização, aspecto fundamental para o efetivo alcance da Inteligência Organizacional e Competitiva (IOC) . 


\section{REFERÊNCIAS}

ALBRECHT, K. Um modelo de Inteligência Organizacional. HSM Management, São Paulo, n.44 mai.-jun. 2004.

ALVES, R. de P.; FALSARELLA, O. M. Modelo conceitual de inteligência organizacional aplicada à função manutenção. Gestão e Produção (UFSCar), São Carlos, v. 16, p. 313-324, 2009.

ANTHONY, R. N.; GOVINDARAJAN, V. Management control systems. 12ed. Boston: McGraw-Hill/Irwin, 2006.

ANSOFF, H. I.; McDONNELL, E. J. Implantando a administração estratégica. São Paulo: Atlas, 1993.

BATAGLIA, M. da G. B. A Inteligência competitiva modelando sistemas de informação de clientes - Finep. Ciência da Informação, v.29, p. 200-214, mai/ago, 1999.

CANONGIA, C.; LAMB, C.; CARVALHO, C.S. de P.; SILVA, V. S. e.Convergência da inteligência competitiva com construção de visão de futuro: proposta metodológica de sistema de informação estratégica: SIE. Datagramazero: Revista de Ciência da Informação, Rio de Janeiro, v. 2, n. 3, jun. 2001.

DI SERIO, L. C.; VASCONCELLOS, M. A. de. Estratégia e competitividade empresarial: inovação e criação de valor. São Paulo: Saraiva, 2009.

DRUCKER, P. F. Administrando em tempos de grandes mudanças. São Paulo: Pioneira, 1995, 230 p.

FALSARELLA, O.M. Modelo de análise e planejamento de tecnologia de informação para instituições de ensino superior. 2001. 184f. Tese (Doutorado em Engenharia Mecânica) - Engenharia Mecânica, Universidade Estadual de Campinas, Campinas, 2001.

FALSARELLA, O. M.; BERAQUET, V. S. M.; JANNUZZI, C. A. S. C.Informação empresarial: dos sistemas transacionais à latência zero. In: BERAQUET, V.S.M.; CIOL, R. (Org.). O profissional da informação na gestão - uma coletânea. Campinas: Akademika, 2010, v.1, p. 31-54.

FULD, L. M. The new competitor intelligence: the complete resource for finding, analyzing and using information about your competitors. New York: John Wiley \& Sons, 1994.

FULD, Leonard M. Inteligência competitiva: como se manter á frente dos movimentos da concorrência e do mercado. 1 ed. Rio de janeiro: Elsevier Campus, 2007. $256 \mathrm{p}$. 
KWASNICKA, E.L. Introdução a administração. 6.ed. São Paulo: Atlas, 2004.

JANNUZZI, C. A. S. C. ; TÁLAMO, Maria de Fátima Gonçalves Moreira. A empresa e os sistemas humanos de informação: uma abordagem conceitual para a gestão da informação. Transinformação, Campinas - SP, v. 16, n.16, p. 171-187, 2004.

LAKATOS, E. M.; MARCONI, M. de A. Metodologia do trabalho científico. 7 ed. São Paulo: Atlas, 2007.

MAXIMIANO, A. C. A. Teoria Geral da Administração: da revolução urbana à revolução digital. 3. ed. São Paulo: Atlas S.A., 2000.

MINTZBERG, H.; QUINN, J.B. O processo da estratégia.3 ed. Porto Alegre, RS: Bookman, 2001.

MONTANA, P.J.; CHARNOV, B.H. Management. 4ed. New York: Barron's, 2008. MORESI, E.A.D. Inteligência Organizacional: um referencial integrado. Ciência da Informação, Brasília, v.30, n.2, p.35-46, mai./ago. 2001.

O‘BRIEN, J. A.; MARAKAS, G. M. Administração de Sistemas de Informação.15ed. Porto Alegre: AMGH/McGraw-Hill/Bookman, 2013.

OLIVEIRA, P.H. de; GONÇALVES, C.A.; PAULA, E.A.M. de. A visão baseada em recursos da inteligência. Revista de Ciências da Administração, Florianópolis, v.15, n.35, p.141-151, abr. 2013.

PORTER M. E. Estratégia competitiva:Técnicas para analise de indústrias e da concorrência. 17.ed. Rio de Janeiro: Campus Elsevier, 2005. 409 p.

PRESCOTT, John E. The evolution of competitive intelligence: Designing a process for action, Proposal Management, APMP Spring, 1999, p. 37-52.

REZENDE, D.A. Tecnologia de informação integrada à inteligência empresarial: alinhamento estratégico e análise da prática nas organizações. São Paulo: Atlas, 2002.

RIZZO, G. de A.; FALSARELLA, O. M. Estrutura Informacional para Monitoramento do Planejamento Estratégico Apoiado no Balance Scorecard.eGesta - Revista Eletrônica de Gestão de Negócios, Santos, v.2, n.2, p.113-137, mai./ago. 2006.

STAREC,C.Gestão estratégica da informação e inteligência competitiva. São Paulo: Saraiva, 2006. 351 p.

STONER, J. A. F. Administração. 2 ed. Rio de Janeiro: Prentice- Hall do Brasil, 1995. TARAPANOFF, K. Referencial teórico: introdução. In: TARAPANOFF, K. (Org.). Inteligência organizacional e competitiva. Brasília: Editora da Universidade de Brasília, 2001. p. 265-278. 
TARAPANOFF, K. Inteligência social e inteligência competitiva. Revista Eletrônica de Biblioteconomia e Ciência da Informação, Florianópolis, n. esp, $1^{\text {o }}$ sem., 2004. Disponível em http://www.periodicos.ufsc.br/index.php/eb/issue/view/101

THOMPSON, A.A; STRICKLAND III, A.J.; GAMBLE, J.E. Administração Estratégica. 15 ed. São Paulo: McGraw-Hill, 2008.

VALENTIM, M. L. P. et alii. O processo da inteligência competitiva em organizações. DataGramaZero - Revista de Ciência da Informação. V.4, n.3, p. 1-23, jun. 2003. Disponível em: <http://www.dgz.org.br/jun03/Art_03.htm>. Acesso em: 07 de março de 2013.

FALSARELLA, Orandi Mina; JANNUZZI, Celeste Aída Sirotheau Corrêa; SUGAHARA, Cibele Roberta. Planejamento estratégico empresarial: proposta de um sistema de inteligência organizacional e competitiva. Rev. digit. bibliotecon. cienc. inf., Campinas, SP, v.12, n.2, p., mai./ago. 2014. ISSN 1678-765X. Disponível em: <http://www.sbu.unicamp.br/seer/ojs/index.php/rbci>. Acesso em:

Como citar este documento:

FALSARELLA, Orandi Mina; JANNUZZI, Celeste Aída Sirotheau Corrêa; SUGAHARA, Cibele Roberta. Planejamento estratégico empresarial: proposta de um sistema de inteligência organizacional e competitiva. Rev. digit. bibliotecon. cienc. inf., Campinas, SP, v.12, n.2, p.193-216, mai./ago. 2014. ISSN 1678-765X. Disponível em: <http://www.sbu.unicamp.br/seer/ojs/index.php/rbci>. Acesso em: 30 maio 2014. 